\title{
Numerical analysis of strengthening concrete columns by high performance fibre concrete
}

\author{
Martin Vavruš ${ }^{1}$, Peter Koteš ${ }^{1, *}$, and Ashot Tamrazyan ${ }^{2}$ \\ ${ }^{1}$ University of Žilina, Faculty of Civil Engineering, Univerzitná 8215/1 1026 Zilina, Slovakia \\ ${ }^{2}$ Moscow State University of Civil Engineering, Yaroslavskoe shosse, 26, Moscow, 129337, Russia
}

\begin{abstract}
Concrete is a material that has advantages and disadvantages. High strength in pressure, as well as increased mechanical resistance are its advantages, on the other side, it has a lower tensile strength as its disadvantage. This is related with creating cracks, when concrete in a tensile zone occurs plasticisation of reinforcement (provided that members are reinforced) which is in consequence of depletion carrying capacity associated with creating plastic hinge and exceed his rotation capacity. Following, the cross-section has a lower carrying capacity. Strengthening of jacketing by fibre-concrete has provided with reducing width of cracks an increasing of carrying capacity cross-section at minimal increasing of the columns slenderness.
\end{abstract}

\section{Introduction}

Every construction is loaded by dead load or by other permanent and variable loads. Every load performs stress states and internal forces. Every member is dimensioned on expected loads and design lifetime $T_{d}$. Cracks are created after exceeding the tensile strength of concrete and they decrease his load-carrying capacity. Damaged member is not able to satisfy the limit states and subsequently, it is needed to reconstruct the member. By properly selected way of strengthening, is able to remove damages, which result from excessive loading. Jacketing by fibre-concrete layer is one of the ways of strengthening.

Fibre-concrete is cementation composite material made of the basic components (aggregate, water, cement, additives and admixtures) and added fibres [1]. Wide spectrum of fibres allows to alter concrete properties. In this article, it deals with strengthening by fibre-concrete, and specifically, strengthening by adding steel fibres. Added fibres change behaviour of the concrete, where it occurs to transformation from brittle concrete on ductile concrete, which is able to resist enormous strains without loss resistance. Practically it means that tensile force transferred by concrete before creating crack has to able to transfer bigger tensile forces to avoid the collapse of the structure after creating cracks. Important factor is increasing ductility, which provides energy absorption to the mechanism, where at creating first crack decreasing or increasing ductility occurs. If it is prevented to failure at this stage, bending capacity of the fibres should be bigger than load at first crack. Concrete composite itself can soften or harden so called softening or hardening. So it is getting to

* Corresponding author: kotes@fstav.uniza.sk 
post-cracking stage which allows to multiply the cracks. Order of experiments with fibreconcrete shows that after creating first crack in bending members will not get to create other cracks, however, the first crack will constantly extend until collapse of the structures will occur. This process is for separate reinforcement members. In large quantities of materials damage occurs because of crack extension. Material model 3D Nonlinear cementations 2 for concrete, which describes the behaviour in tensile is characterised by nonlinear fracture mechanics in combination with width crack method and at suitable calibration it describes behaviour of fibre-concrete very well (Figure 1).
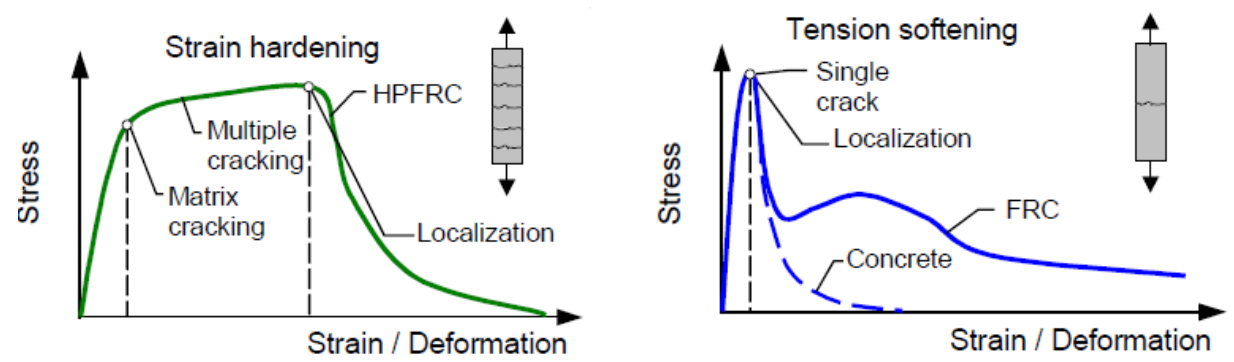

Fig. 1. Stress - deformation graph

\section{Numerical experiments}

For experimental analysis, the reinforced concrete (RC) column with height $2.5 \mathrm{~m}$ was taken into account. Column has ground plan dimension $240 \times 240 \mathrm{~mm}$. Within experiment concrete type $\mathrm{C} 16 / 20$ was chosen, which means that his strength in pressure is $16 \mathrm{MPa}$, strength in tensile is $1.9 \mathrm{MPa}$ and modulus of elasticity $29 \mathrm{GPa}$. Column is reinforced by reinforcement B 500B (4 bars in corners) with diameter $10 \mathrm{~mm}$ and by stirrups with diameter $8 \mathrm{~mm}$ with spacing $100 \mathrm{~mm}$. Providing that minimum and maximum of reinforcement ratio $\varrho_{\min }=0.002 \leq \varrho=0.00545 \leq \varrho_{\max }=0.04$ was respected. According to $\mathrm{STN}$ EN 1992-1-1, the concrete column can carry pressure of about $214.72 \mathrm{kN}$ and bending moment $19.36 \mathrm{kN}$.m. On the basis of that, the eccentricity was determined on value 101 $\mathrm{mm}$ from the center of the gravity of cross-section and determined slenderness on value 36.23. FEM model in ATENA program was developed, which consists of reinforced concrete column and bottom plate, on which supports and vertical loading were eccentrically located. There were considered the hinge supports in calculation model, and buckling length equals to length of column. Model has been loaded with alone forces on eccentricity. Subsequently, the strengthening models of column were also considered. First alternative has been strengthened by jacketing using fiber-concrete layer around the column. On jacketing, the material characteristics of fiber-concrete given in [2] were used, because of the reason that for description of the fracture process of such materials is advisable to do a lot of experiments and subsequently adapt model parameters towards required values that the results approach to the experimentally detected values. In the article, modeling fiber-concrete is described by changed materials values. Test was realized, when concrete mixtures achieved strength in pressure after 28 days $46 \mathrm{MPa}$ in which $40 \mathrm{~kg} / \mathrm{m}^{3}$ fibers types ARCELOR HE 75/50 was added. Subsequently, analysis of real state and modifying of material characteristics for reaching real acting in calculation model was performed. To address the measured values and calculation values, it was necessary to increase fracture energy to 60 times of the original values for plain concrete and as well tensile strength to 0.66 times. In Table 1, values for considered materials characteristics from [2] are shown. 
Table 1. Results of the modify materials characteristics.

\begin{tabular}{|l|c|}
\hline \multicolumn{2}{|l|}{ 3D Nonlinear Cementations 2 } \\
\hline Stress modulus [MPa] & $3.586 \mathrm{E}+04$ \\
\hline Poisson's numbers [-] & 0.20 \\
\hline Strength in tensile [MPa] & $2.00 \mathrm{E}+00$ \\
\hline Strength in compresive [MPa] & $-3.91 \mathrm{E}+01$ \\
\hline Specific fracture energy [MN/m] & $3.75 \mathrm{E}-02$ \\
\hline Critical pressure deformation $[\mathrm{m}]$ & $-2.50 \mathrm{E}-01$ \\
\hline
\end{tabular}

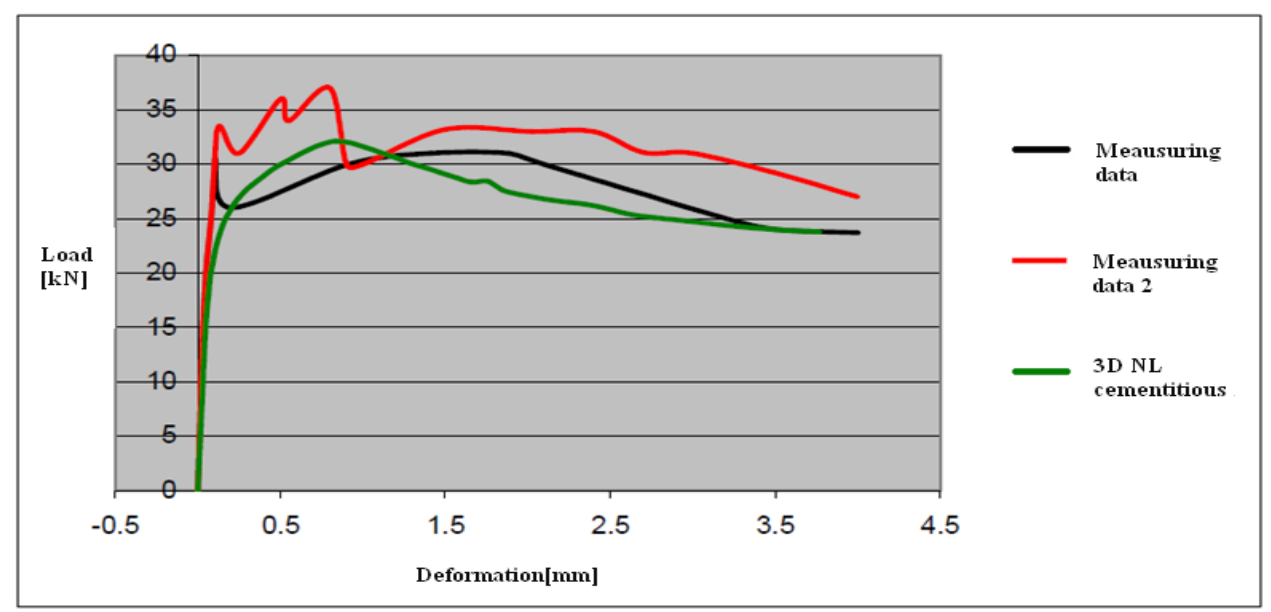

Fig. 2. Modification of measured samples and compare with ATENA

Subsequently, such modified data have been applied to a calculation model of column. In the first type of considered strengthening, the column has been jacketed (strengthened) with $30 \mathrm{~mm}$ thick fiber-concrete after whole height. His slenderness declines on value 28.73 from 36.23 what is about $20.7 \%$ decreasing against original size. For further comparison another type of strengthening has been developed, which has been jacketed as well with the concrete $\mathrm{C} 40 / 50$. The coherence has been considered equally to previous case. The resistance of the column has been calculated according to STN EN 1992-1-1 for theoretical comparison with the results from ATENA. Consequential strength towards fiber-concrete is different about $8 \mathrm{MPa}$.

\section{Comparing the results}

Three models are for comparing. In the case of first model (RC non-strengthened column), there was reached the maximum load $315 \mathrm{kN}$ up to failure, what is about $32 \%$ higher 
resistance opposite calculating according to STN EN 1992-1-1. In the second model, strengthened model using jacketing with fiber-reinforced concrete has reached $491 \mathrm{kN}$ (Figure 3). Increase of resistance is about 35\% opposite non-strengthened RC model. The third model has been for comparison - using just normal concrete but of higher strength. Resistance full cross-section $300 \times 300 \mathrm{~mm}$ was equal to $360 \mathrm{kN}$. This achieved value is only theoretical for reason that was not taken into account the parameter of contact between original cross-section and new jacketing layer around the cross-section. There was considered rigid contact. The resistance was increasing about $40.6 \mathrm{kN}$ in comparison with STN EN 1992-1-1. The difference was about $18.34 \%$ with compare to jacketing highstrength concrete class C40/50 (Figure 4).

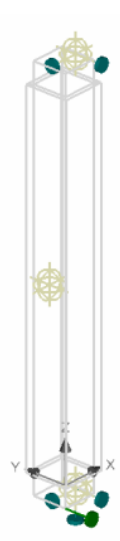

a) FEM - model b) Deformation
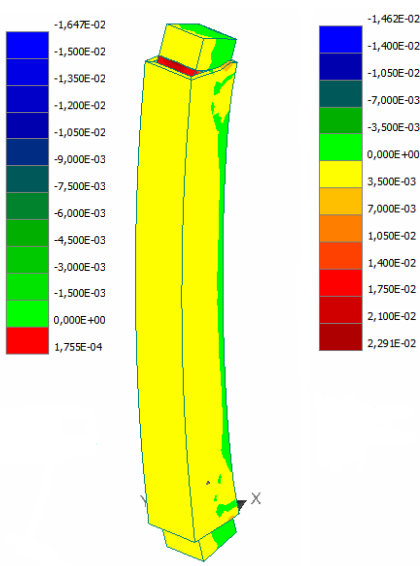

c) Strain

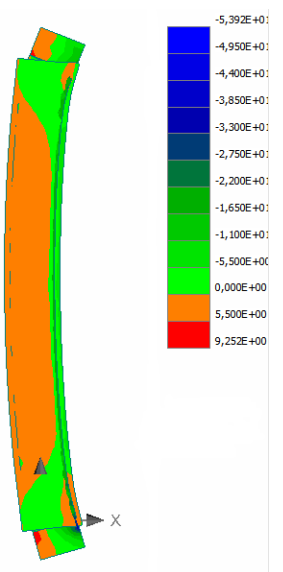

d) Stresses

Fig. 3. Internal states from ATENA

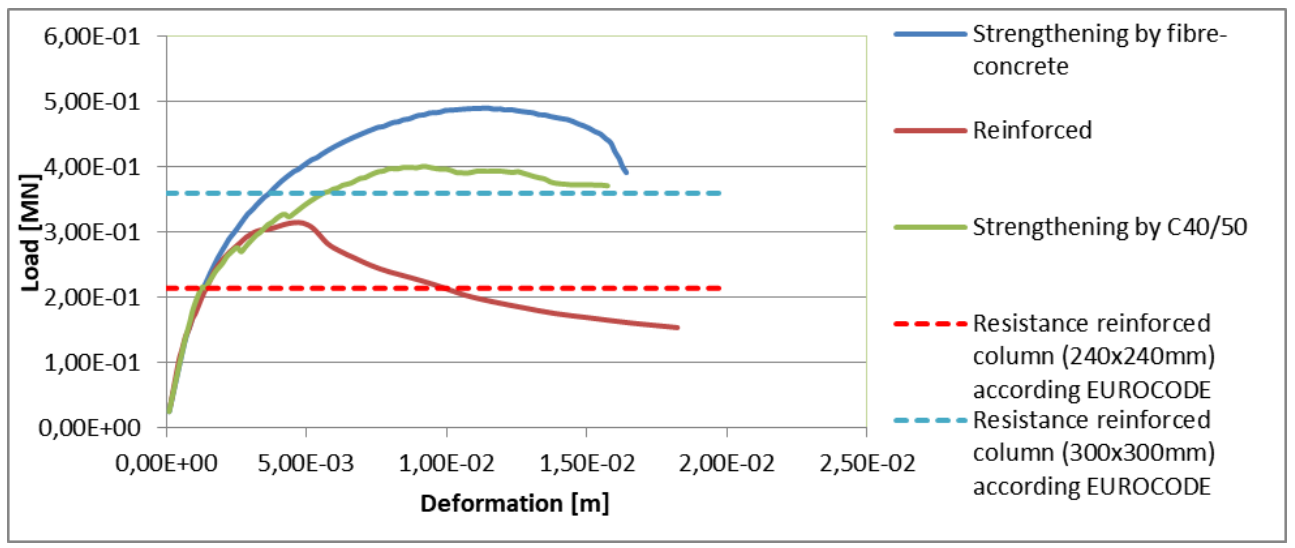

Fig. 4. Comparison of individual methods/models

\section{Comparing contact of the stiffness initial with new concrete}

The contact between old concrete core of column and new concrete layer (shear connection) is very important element. Program ATENA allows change stiffness these 
contact. For comparison, there has been compared three samples where the stiffness has been changing according to following ratios

$$
K_{n n}=\frac{E}{t}, K_{t t}=\frac{G}{t}
$$

where $E$ is the modulus of material elasticity, $G$ is the shear modulus of material elasticity and $t$ is a theoretical thickness layer between initial and new concrete.

The values are usually established on a basis of real exams or iterations. For theoretical determination, the samples have been compared, when the stiffness $\mathrm{K}_{\mathrm{nn}}$ and $\mathrm{K}_{\mathrm{tt}}$ were changed and subsequently (Figure 5).

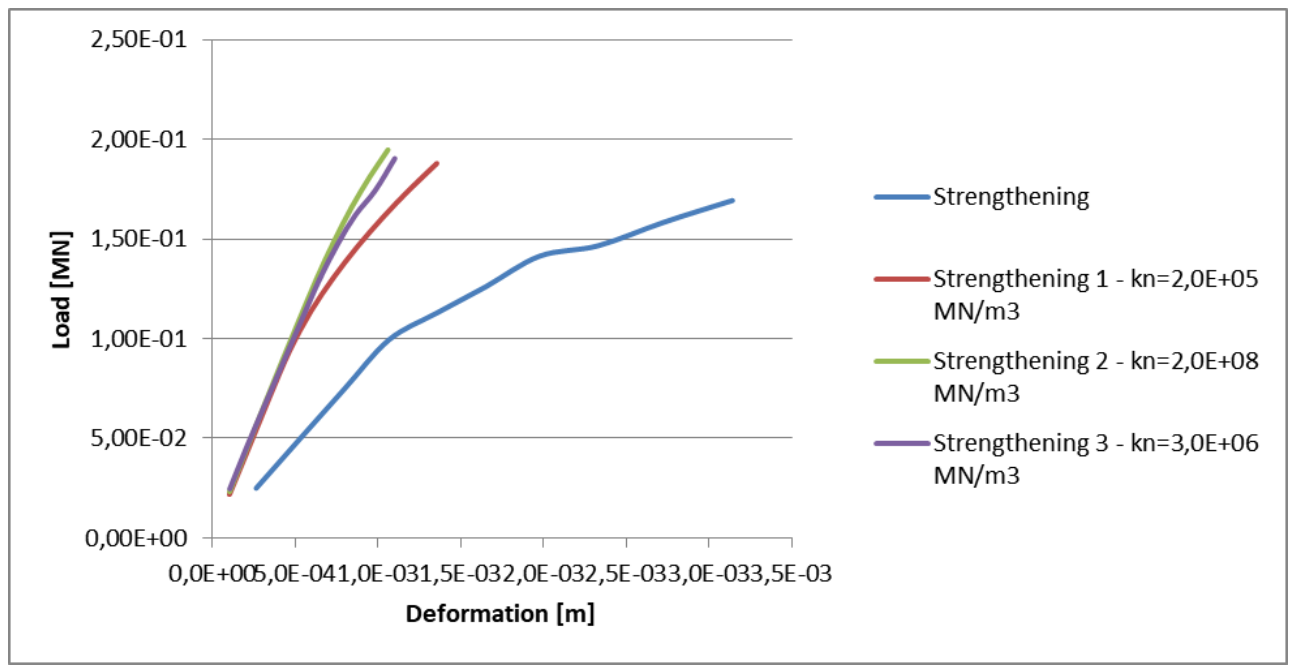

Fig. 5. Comparing stiffness individual

Concrete is a nonlinear material $[3,4,5]$, which is characterized by compressibility and different stiffness has caused increasing or decreasing the resistance of whole strengthened cross-section. It means that if shear resistance (contact parameters) is bigger, also resistance of cross-section is higher.

\section{Summaries}

As shown in Tab. 2, from compared results of strengthened models follow that jacketing method by fiber-concrete is a better variant. Results are satisfactory when resistance was increasing about $36 \%$. It is also possible to confirm, that the resistance was increasing about $91 \mathrm{kN}$ using the fibers opposite using concrete of class C40/50. Its resistance increased about $24 \%$. Both variants brought satisfactory results. No need to forget that contact surface between individual materials had a large influence on resistance. 
Table 2. Results individual strengthening methods.

\begin{tabular}{|l|c|c|c|}
\hline & $\begin{array}{c}\text { Force } \\
{[\mathbf{k N}]}\end{array}$ & $\begin{array}{c}\text { Deformation } \\
{[\mathbf{m}]}\end{array}$ & $\begin{array}{c}\text { Strengthening opposite } \\
\text { STN EN 1992-1-1 [\%] }\end{array}$ \\
\hline $\begin{array}{l}\text { Non-strengthened model } \\
\text { STN EN 1992-1-1 }\end{array}$ & 214 & - & - \\
\hline $\begin{array}{l}\text { Non-strengthened model } \\
\text { ATENA }\end{array}$ & 315 & 0,00438 & 32,06 \\
\hline $\begin{array}{l}\text { Strengthened model } \\
\text { according to STN EN } \\
1992-1-1\end{array}$ & 360 & - & - \\
\hline $\begin{array}{l}\text { Strengthening by fiber- } \\
\text { concrete layer }\end{array}$ & 491 & 0,0111 & $35,88^{*}$ \\
\hline $\begin{array}{l}\text { Strengthening by layer of } \\
\text { concrete C40/50 }\end{array}$ & 410 & 0,00877 & $23,17 *$ \\
\hline
\end{tabular}

* [\%] compare with reinforcement model ATENA

\section{Conclusions}

The paper deals with one of many strengthening methods of concrete columns. Theoretically, there has been demonstrating, that jacketing by fiber-concrete layer has majority efficient like jacketing by only high-strength concrete layer. Moreover, the change of the contact stiffness of connection has negligible influence on resistance in compression. It means that surface treatment before execution of a project is very important. Results show, that using fiber-concrete is not still explored so much and it has a great potential in variability of added fibers and for strengthening. We have to highlight, that interaction mechanism between fiber and concrete can be after cracks occurring different. The volume added fibers is next thing that affects the results in this type of strengthening - there was considered $40 \mathrm{~kg} / \mathrm{m}^{3}$ fibers. The increasing ductility and resistance of cross-section are predicted by increasing volume fiber.

\section{References}

1. I. Hudoba, High-performance concrete, Materials, properties, producing, utilization, 163 (2008)

2. T. Sajdlová, Fiber-concrete - determination parameters materials models (2011)

3. J. Eliáš, J. Láník, M. Vořechovský, Short educational video recordings for courses of nonlinear fracture mechanics (2009)

4. V. Veselý, Parameters of concrete for description of fracture behaviour (2005)

5. Z. Kerner, Brittleness and fracture mechanics of cement-based composites (2005) 